\title{
Article \\ Applications of Energy-Based Evaluation Method of Element Importance to Grid Structures
}

\author{
Liwu Wang ${ }^{1,2}$, Jian Feng ${ }^{1}$, Yixiang $\mathrm{Xu}^{3}$, Liping Zhuang ${ }^{1}$, Qian Zhang ${ }^{1}{ }^{\mathbb{C}}$ and Jianguo Cai ${ }^{1, *}$ \\ 1 Key Laboratory of C \& PC Structures of Ministry of Education, National Prestress Engineering Research \\ Center, Southeast University, Nanjing 211189, China; 230188228@seu.edu.cn (L.W.); fengjian@seu.edu.cn (J.F.); \\ 220100852@seu.edu.cn (L.Z.); z.qian@seu.edu.cn (Q.Z.) \\ 2 Beijing Institute of Space Mechanics \& Electricity, Beijing 100094, China \\ 3 School of Aerospace, The University of Nottingham Ningbo China, Ningbo 315100, China; \\ yixiang.xu@nottingham.edu.cn \\ * Correspondence: j.cai@seu.edu.cn
}

check for updates

Citation: Wang, L.; Feng, J.; Xu, Y.; Zhuang, L.; Zhang, Q.; Cai, J. Applications of Energy-Based Evaluation Method of Element Importance to Grid Structures. Symmetry 2022, 14, 370. https:// doi.org/10.3390/sym14020370

Academic Editor: Raffaele Barretta

Received: 21 January 2022

Accepted: 10 February 2022

Published: 13 February 2022

Publisher's Note: MDPI stays neutral with regard to jurisdictional claims in published maps and institutional affiliations.

Copyright: (C) 2022 by the authors. Licensee MDPI, Basel, Switzerland. This article is an open access article distributed under the terms and conditions of the Creative Commons Attribution (CC BY) license (https:// creativecommons.org/licenses/by/ $4.0 /)$.

\begin{abstract}
It is necessary to perform the robustness design for the progressive collapse resistance of grid structures. However, there is a lack of a comprehensive index to evaluate the member importance. An evaluation method on element importances is proposed based on the element strain energy and element removal technology. The element importance coefficients can be calculated based on the change of strain energy vectors after the removal of analyzed elements using ANSYS. The influence of the loading pattern, boundary condition, and geometric parameters of square pyramid grid structures are investigated. Moreover, the other three types of spatial grids are introduced to explore the difference in element importance distributions. The considerable difference in element importance coefficient distribution for different grid structures shows that it is essential to establish a general program for rapid model robustness analysis. This principle in this work can be easily integrated into the existing design and analysis platform to make up for this shortcoming.
\end{abstract}

Keywords: grid structure; importance coefficient; robustness; strain energy; progressive collapse

\section{Introduction}

Over recent decades, with the sudden increase of accidents and terrorist activities, some progressive collapse accidents have occurred, causing serious casualties, property losses, and social impacts [1-4]. The safety of the structure has drawn paramount attention. The study of structural progressive collapse resistance has become a hot topic in research worldwide [5-11].

However, most of these research outputs are focused on frame structures, and there are fewer studies on the progressive collapse of space structures. A 3D finite element model of a double-layer space structure grid was built to investigate structural behavior, and several collapse scenarios were examined following the alternative path method defined in GSA [12]. The anti-progressive collapse mechanism of long-span single-layer spatial grid structures was investigated by constructing a model of substructures with eight full-scale test specimens [13]. A method, including kinked steel pipe reinforcement and extra member reinforcement, was proposed to improve the resistance of a single-layer spatial grid structure [14]. A review of the main advances made in the 21st century in the field of robustness and progressive collapse of building structures was carried out by Adam et al. [15]. This review pointed out that some areas still required deeper study, such as the evaluation of structures and decision making after a failure.

Understanding the behavior of structural elements is the basis for studying structural robustness. The structural robustness here refers to the performance of the structure against the impact of sudden events and the progressive collapse. It is easier to explain the safety of the structure under the impact load with small probability, but serious consequences [16]. 
The importance index of the element can reflect not only the impact of individual element damage caused by sudden incidents on the overall structural performance, but also one of the key points of the analysis of load path analysis. The element importance is not only related to the properties of the structure itself, but also to the external loads that the structure is subjected to. Wu et al. [17-19] proposed the theory of the structural vulnerability assessment. Then, an assessment method based on the sensitivity analysis was established by Pandey [16]. The main approach is to calculate the sensitivity coefficient of the structure based on the change of the structure under the initial damage caused by the sudden event. It is found that the structural redundancy is inversely proportional to the sensitivity of the element. Beeby and Institution [20] proposed permissible energy per unit volume based on structural energy. By specifying the lower limit of the allowable damage energy per unit volume limit, the structure ensures a certain deformation capacity of the structure, and no overall collapse occurs in an emergency. Gharaibeh et al. [21] established the system reliability theory on the influence of elements on reliability. The reliability theory is relatively complete and is used in various structural systems to simplify calculations by a large number of data statistics and assumptions of various factors such as load, material, and strength. Izzuddin et al. [22] proposed a simplified approach for the progressive collapse assessment of multi-story building structures, considering sudden column loss as a design scenario, offering, for the first time, a quantitative framework for the consideration of such important issues as ductility, redundancy, and energy absorption. It was found that the determinant of the stiffness matrix of the structure is closely related to the safety of the structure, and the importance coefficient of the element can be defined from the material stiffness matrix of the structure [23]. Based on previous research about the robustness, new theories or methods to element importance have been proposed successfully using new judgment indicators, where most are for frame structures, and a few are for grid structures [24-29].

It can be found from the literature that there is a lack of a rapid evaluation method for the robustness of grid structures, which is essential in the conceptual analysis stage after the preliminary design of the grid structures. In this paper, structural strain energy is selected as an index to determine the element importance, which can reflect the influence of geometry, topology and external loads simultaneously. Moreover, element removal technology is introduced to achieve rapid parametric evaluation. The square pyramid space grid is chosen to illustrate the proposed method in Section 3. Then, the distribution of important elements under different load patterns, support conditions, and spatial geometric parameters are studied in Section 4. Three types of spatial grids, diagonal square pyramid grids, bi-orthogonal lattice grids, and bi-orthogonal-diagonal lattice grids, are also chosen to study the influence of the topology on the element importance in Section 5. Section 6 draws the conclusion.

\section{Evaluation Method of Element Importance}

The accident that results in the progressive collapse of the grid structure is mostly attributable to the structural response to the initial element failure. Therefore, the initial failure is assumed to be one element removed. As the number of elements of the grid structures is large, it is computationally expensive to consider all members to be removed. As a result, a method for determining element importance should be proposed.

\subsection{Hypothesis}

In structural conceptual design or early design, the approach for evaluating element importance is applied. In this paper, the following hypothesis is assumed.

1. Only linear elasticity and geometric nonlinearity are introduced in the analysis, while material damage and structural stability are not taken into account.

2. The topological relationship will be modified by the conceptual removal method in the numerical simulation for the initial damage. The additional load and dynamic effects induced by falling and explosion are not included. 
3. In the event of an accident, the structure is rarely damaged by earthquake and wind loads simultaneously. As a result, only the vertical nodal load is taken into the evaluation.

4. The external loads at the nodes are not affected by the failure of elements in the grid structures.

\subsection{Element Importance Coefficient}

Based on the sensitivity analysis theory [16], the importance coefficient of element $i$, $\alpha_{i}$, is defined as

$$
\alpha_{i}=\left|1-\frac{\left\|V_{\varepsilon o}\right\|_{1}}{\left\|V_{\varepsilon d i}\right\|_{1}}\right|
$$

where $V_{\varepsilon o}$ and $V_{\varepsilon d i}$ are the element strain energy vectors of the undamaged structure and damaged structures after removing element $i$, respectively. The element strain energy can be defined as follows.

$$
V_{\varepsilon}=\frac{N^{2} l}{2 E A}=\frac{E A(\Delta l)^{2}}{2 l}=\frac{1}{2} \sigma \varepsilon v=\frac{\sigma^{2} v}{2 E}=\frac{E \varepsilon^{2} v}{2}
$$

where $N, l$ and $\Delta l$ are the axial force, the original length and the length variation of the element, respectively. $A$ and $v$ are the corresponding section area and volume. Besides, $E, \varepsilon$ and $\sigma$ are the elastic modulus, strain and stress, respectively.

The range of the element importance coefficient $\alpha_{i}$ is set to be $[0,1]$. When $\alpha_{i}$ is equal to be 0 , there is almost no change in the strain energy after removing element $i$, indicating that the contribution of element $i$ to the load transfer path is very small. A smaller coefficient $\alpha_{i}$ indicates there are more redundant constraints. It means that after the element is removed, there are more alternative force transmission paths to redistribute the external load to other parts of the structure. On the contrary, a greater importance coefficient $\alpha_{i}$ represents that the element is a minor subject to redundant constraints. It suggests that fewer force paths can be replaced in the remaining structure, and the load undertaken by the element is difficult to redistribute to other parts of the structure. When the coefficient $\alpha_{i}$ is close to 1 , the deformation of the remaining structure becomes significant. It indicates there is higher stored strain energy.

\subsection{Flow Chart of the Method}

The steps of the evaluation method of element importance based on the strain energy are shown in Figure 1. Firstly, the linear elastic static analysis of the undamaged grid structure is carried out to get the element strain energy vector. Secondly, the elements that need to be evaluated are chosen based on the symmetry of the grid structure. Then, each selected element is removed in turn, and the linear elastic static analysis is performed on the corresponding remaining structure to calculate the strain energy. After that, the important coefficient for each element is obtained based on the method given in this paper. The element importance coefficient can be used to determine the initial loss for the progressive collapse analysis of the grid structures. Moreover, elements with higher importance coefficients could be strengthened to increase the robustness of the structures.

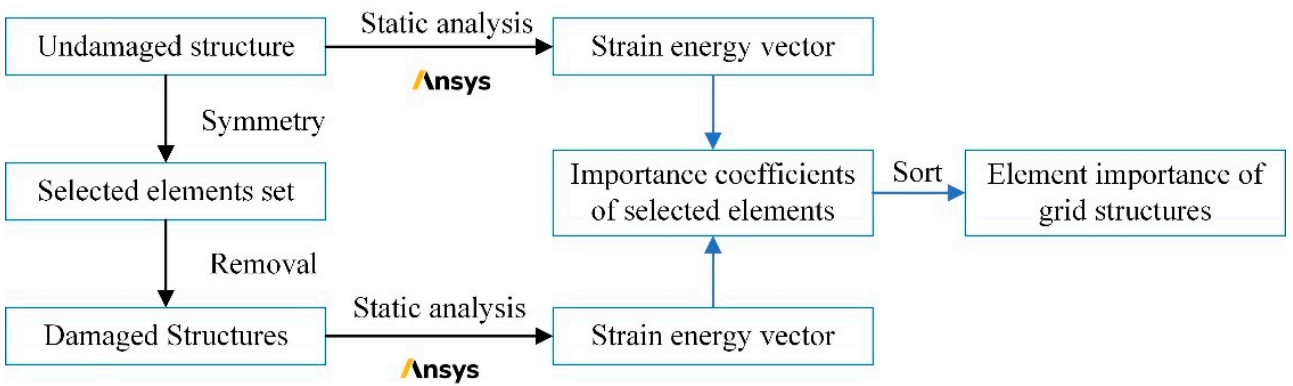

Figure 1. Flow diagram of the evaluation method. 
Software ANSYS is chosen for the numerical simulation, and it is easier to establish parametric models of the grid structure using APDL descriptive language. Birth-death element technology is adopted to simulate the removal of the element.

\section{Element Importance of Square Pyramid Space Grid Structures}

The element importance of a square pyramid space grid structure, depicted in Figure 2, is studied in this section. The planar dimension of the analyzed grid is $40 \mathrm{~m} \times 40 \mathrm{~m}$, with the grid number in both directions of 10 and the grid length of $4 \mathrm{~m}$. The height of the grid structure and the upper chord and lower chord members are steel tubes with $\Phi 159 \mathrm{~mm} \times 8 \mathrm{~mm}$ (diameter $\times$ thickness), while the diagonal web members are steel tubes with $\Phi 114 \mathrm{~mm} \times 4 \mathrm{~mm}$ (diameter $\times$ thickness). Q235 steel is used for the tubes with a Young's modulus of $2.1 \times 10^{5} \mathrm{MPa}$ and Poisson's ratio of 0.3 . The nodal loads applied at the upper nodes include the dead load of $1 \mathrm{kN} / \mathrm{m}^{2}$ and the live load of $0.5 \mathrm{kN} / \mathrm{m}^{2}$ in the vertical direction. The upper surrounding nodes are fixed in the simulation.

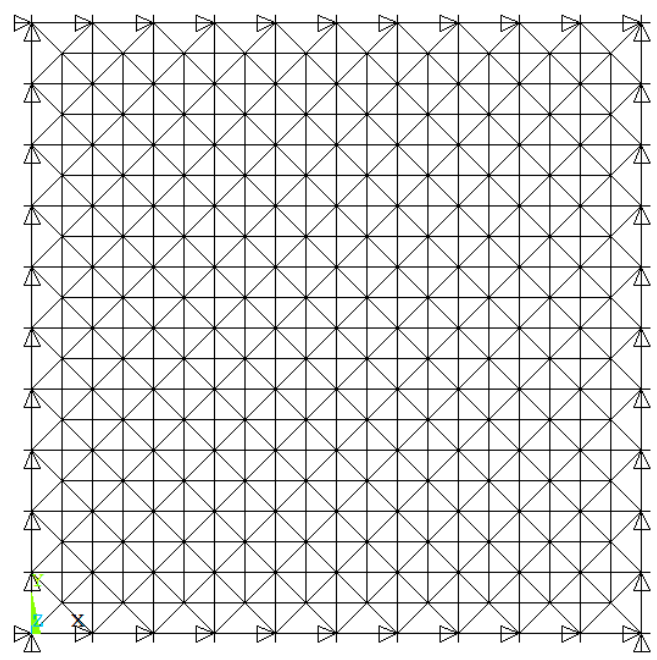

Figure 2. Square pyramid space grid structure.

Given the loads and supports, the square pyramid grid structure is axisymmetric and centrally symmetric. Therefore, only an eighth of the structure was used to investigate the element importance, as shown in Figure 3a. The number of top chords, lower chords and diagonal web members are given in Figure $3 b-d$.

The results of the element importance of the square pyramid spatial grid structure are described in Table 1. It can be seen that the element importance coefficient is relatively small, ranging from 0 to 0.03256 . It indicates that the square pyramid spatial grid structure has good robustness, and it can transfer external loads through many alternative paths. The influence of the loss of one element is slight. The importance coefficient of the lower chord 305 is the largest, and the second-largest is in chord 287. They are located at the center of the lower chord plane. The top chords with high importance coefficients are chords 96 and 93, located at the center, while the important diagonal web members are chords 418 and 419 , close to the supports. It denotes that the lower and top chords are more important than the diagonal web members. The lower or top chords farther away from the support are more important. It is similar for the diagonal web members closer to the support. 


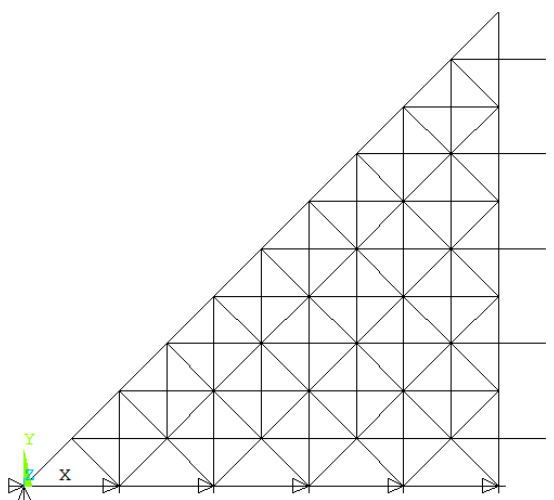

(a)

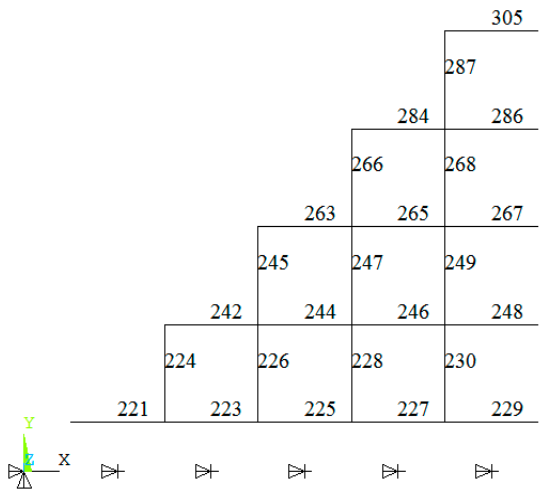

(c)

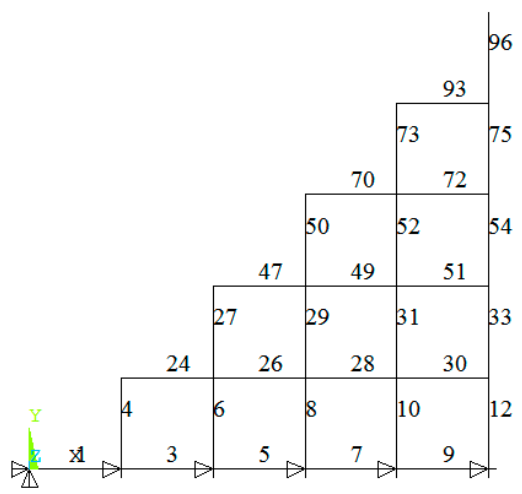

(b)

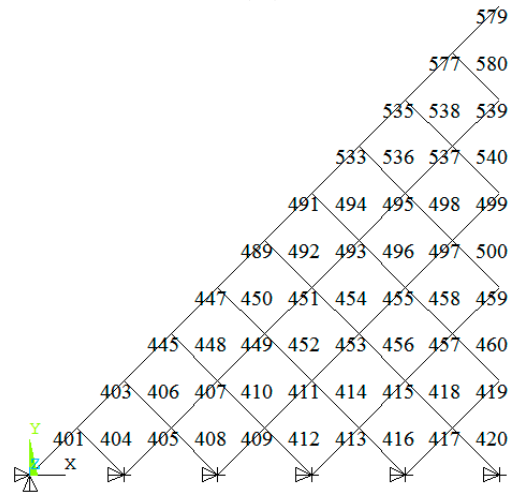

(d)

Figure 3. The eighth of structure system and the number of elements. (a) Eighth structure system; (b) number of top chords; (c) number of lower chords; (d) number of diagonal web members.

Table 1. The importance coefficient of the elements for square pyramid spatial grid structures.

\begin{tabular}{cccccc}
\hline Element Number & $\boldsymbol{\alpha}_{\boldsymbol{i}}$ & Element Number & $\boldsymbol{\alpha}_{\boldsymbol{i}}$ & Element Number & $\boldsymbol{\alpha}_{\boldsymbol{i}}$ \\
\hline 27 & 0.00437 & 228 & 0.00649 & 407 & 0.00113 \\
29 & 0.00779 & 230 & 0.00766 & 409 & 0.00104 \\
31 & 0.01024 & 245 & 0.00905 & 410 & 0.00106 \\
33 & 0.01112 & 246 & 0.00615 & 411 & 0.00160 \\
47 & 0.00720 & 247 & 0.01391 & 413 & 0.00145 \\
49 & 0.00929 & 248 & 0.00647 & 414 & 0.00180 \\
50 & 0.01339 & 249 & 0.01672 & 415 & 0.00204 \\
51 & 0.01036 & 263 & 0.01308 & 416 & 0.00126 \\
52 & 0.01802 & 265 & 0.01569 & 417 & 0.00162 \\
54 & 0.01972 & 266 & 0.02062 & 418 & 0.00223 \\
70 & 0.01762 & 267 & 0.01658 & 419 & 0.00229 \\
72 & 0.01982 & 268 & 0.02510 & 420 & 0.00155 \\
73 & 0.02406 & 284 & 0.02501 & 449 & 0.00106 \\
75 & 0.02645 & 286 & 0.02652 & 453 & 0.00120 \\
93 & 0.02722 & 287 & 0.03066 & 455 & 0.00101 \\
96 & 0.02999 & 305 & 0.03256 & 457 & 0.00117 \\
\hline
\end{tabular}

\section{Influence of Load Pattern and Geometry}

\subsection{Effects of Load Patterns}

Four loading patterns, shown in Figure 4, are introduced to investigate the influence on the element importance of the square pyramid spatial grid structure. The loading pattern is defined as follows: (a) vertical symmetric load with the nodal load of $24.0 \mathrm{kN}$, (b) vertical anti-symmetric load with the nodal load of $24.0 \mathrm{kN}$, (c) half-span vertical load with the nodal load of $24.0 \mathrm{kN}$, and (d) horizontal load with the nodal load of $5.0 \mathrm{kN}$. The element importance distribution of the structure with the vertical symmetric load has been 
reported in Table 1 . The symmetry criteria of the square pyramid space grid structures alter depending on the external load pattern. As a result, semi-structure is selected to consider all load patterns, as illustrated in Figure 5, and the element numbers are also provided.

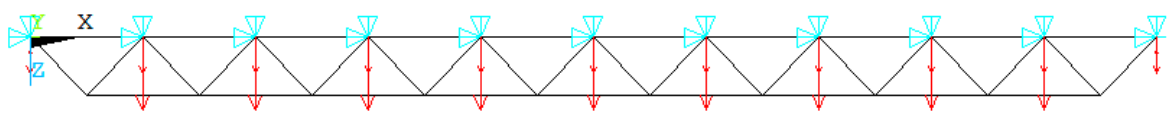

(a)

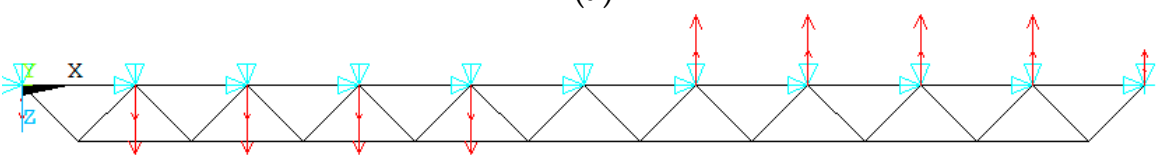

(b)

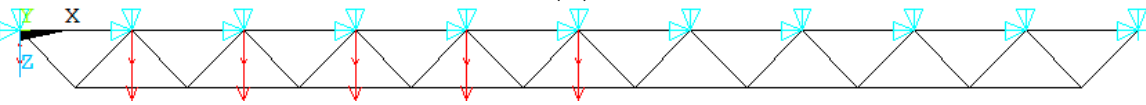

(c)

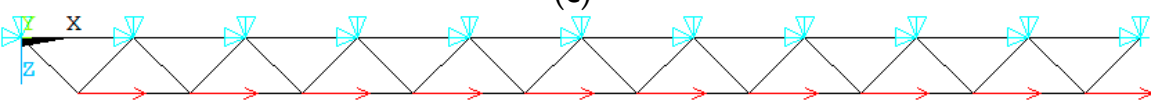

(d)

Figure 4. Four loading patterns. (a) Vertical symmetric load; (b) vertical anti-symmetric load; (c) half-span vertical load; (d) horizontal distributed load.

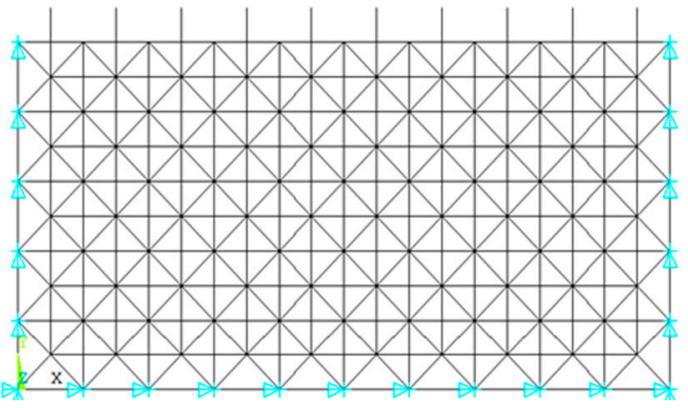

(a)

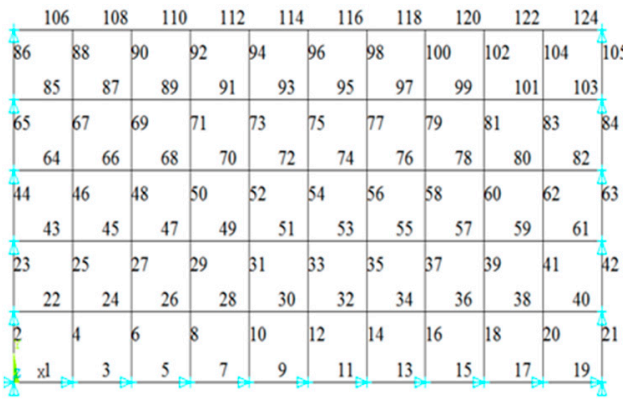

(b)

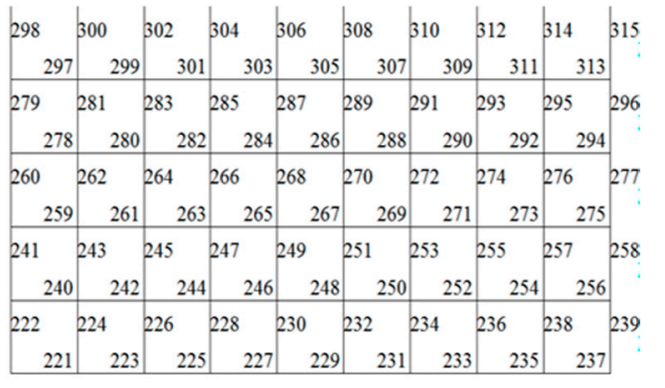

(c)

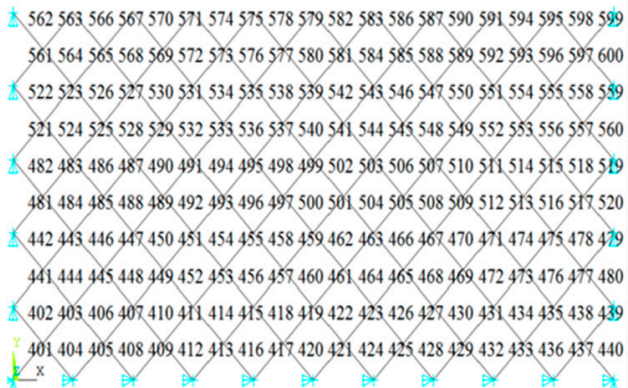

(d)

Figure 5. Semi-structure and its element number. (a) Semi-structure system; (b) number of the top chords; (c) number of the lower chords; (d) number of the diagonal web members.

The importance coefficients of some selected elements of the square pyramid spatial grid structure under different load distributions are given in Tables 2-4. It can be found that the element importance coefficients are changed with the different load patterns. When the structure is subjected to the vertical anti-symmetric load and the half-span vertical load, the corresponding largest element importance coefficient 0.0638 and 0.0406 are higher than the value of the element under the vertical symmetric load. However, the order of importance of the elements is only changed slightly. The importance of the lower and 
upper chords is generally higher than those of the web members, and the lower chord is somewhat more important than the upper chord. However, for the horizontal load, the importance of the web member is generally higher than the upper and the lower chord. The important upper chord members are located near the center along the loading direction, and the important lower chord members are located at the center of the bottom chord plane. Besides, the important members of the web member are located near the periphery of the web member plane.

Table 2. Element importance coefficient $\alpha_{i}$ under the vertical anti-symmetric load.

\begin{tabular}{cccccc}
\hline Element Number & $\boldsymbol{\alpha}_{\boldsymbol{i}}$ & Element Number & $\boldsymbol{\alpha}_{\boldsymbol{i}}$ & Element Number & $\boldsymbol{\alpha}_{\boldsymbol{i}}$ \\
\hline 47 & 0.0275 & 261 & 0.0380 & 483 & 0.0075 \\
66 & 0.0352 & 263 & 0.0390 & 522 & 0.0069 \\
68 & 0.0465 & 278 & 0.0307 & 523 & 0.0093 \\
70 & 0.0377 & 280 & 0.0532 & 524 & 0.0089 \\
87 & 0.0439 & 282 & 0.0553 & 561 & 0.0072 \\
89 & 0.0587 & 284 & 0.0338 & 562 & 0.0075 \\
91 & 0.0481 & 297 & 0.0347 & 563 & 0.0103 \\
108 & 0.0468 & 299 & 0.0608 & 564 & 0.0103 \\
110 & 0.0628 & 301 & 0.0638 & 584 & 0.0066 \\
112 & 0.0516 & 303 & 0.0394 & 544 & 0.0066 \\
\hline
\end{tabular}

Table 3. Element importance coefficient $\alpha_{i}$ under the half-span vertical load.

\begin{tabular}{cccccc}
\hline Element Number & $\boldsymbol{\alpha}_{\boldsymbol{i}}$ & Element Number & $\boldsymbol{\alpha}_{\boldsymbol{i}}$ & Element Number & $\boldsymbol{\alpha}_{\boldsymbol{i}}$ \\
\hline 70 & 0.0267 & 116 & 0.0243 & 306 & 0.0314 \\
72 & 0.0240 & 282 & 0.0329 & 308 & 0.0286 \\
73 & 0.0247 & 284 & 0.0337 & 418 & 0.0030 \\
75 & 0.0249 & 285 & 0.0263 & 422 & 0.0032 \\
89 & 0.0307 & 286 & 0.0268 & 483 & 0.0031 \\
91 & 0.0358 & 287 & 0.0297 & 522 & 0.0026 \\
93 & 0.0325 & 289 & 0.0268 & 523 & 0.0039 \\
94 & 0.0275 & 299 & 0.0292 & 524 & 0.0034 \\
96 & 0.0281 & 301 & 0.0393 & 561 & 0.0030 \\
110 & 0.0333 & 303 & 0.0406 & 562 & 0.0030 \\
112 & 0.0391 & 304 & 0.0276 & 563 & 0.0043 \\
114 & 0.0356 & 305 & 0.0327 & 564 & 0.0042 \\
\hline
\end{tabular}

Table 4. Element importance coefficient $\alpha_{i}$ under the horizontal distributed load.

\begin{tabular}{cccccc}
\hline Element Number & $\boldsymbol{\alpha}_{\boldsymbol{i}}$ & Element Number & $\boldsymbol{\alpha}_{\boldsymbol{i}}$ & Element Number & $\boldsymbol{\alpha}_{\boldsymbol{i}}$ \\
\hline 54 & 0.0010 & 404 & 0.0194 & 416 & 0.0164 \\
73 & 0.0012 & 405 & 0.0215 & 417 & 0.0219 \\
75 & 0.0014 & 406 & 0.0205 & 418 & 0.0214 \\
93 & 0.0014 & 407 & 0.0169 & 420 & 0.0161 \\
96 & 0.0016 & 408 & 0.0182 & 445 & 0.0221 \\
268 & 0.0012 & 409 & 0.0217 & 448 & 0.0183 \\
284 & 0.0012 & 410 & 0.0208 & 449 & 0.0210 \\
286 & 0.0013 & 411 & 0.0159 & 452 & 0.0168 \\
287 & 0.0015 & 412 & 0.0170 & 453 & 0.0208 \\
305 & 0.0016 & 413 & 0.0218 & 456 & 0.0160 \\
401 & 0.0181 & 414 & 0.0212 & 457 & 0.0208 \\
403 & 0.0189 & 415 & 0.0155 & 460 & 0.0156 \\
\hline
\end{tabular}

\subsection{Influence of the Support Conditions}

The influence of the support conditions is also studied in this section. As shown in Figure 6, only the nodes in the two opposite edges are fixed. Then, a quarter-size model is chosen according to the symmetry with the same element number in Figure 5. The calculated element importance coefficients are given in Table 5. 


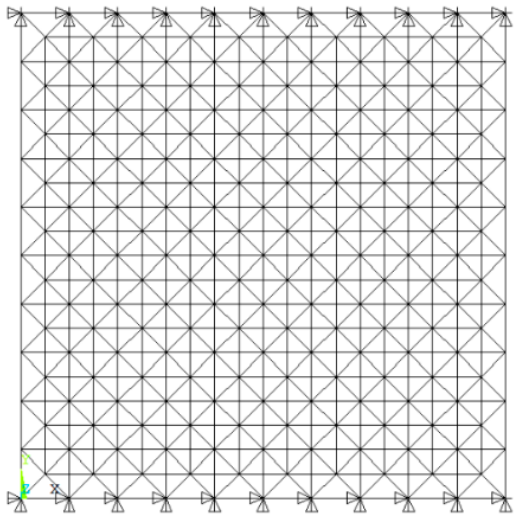

(a)

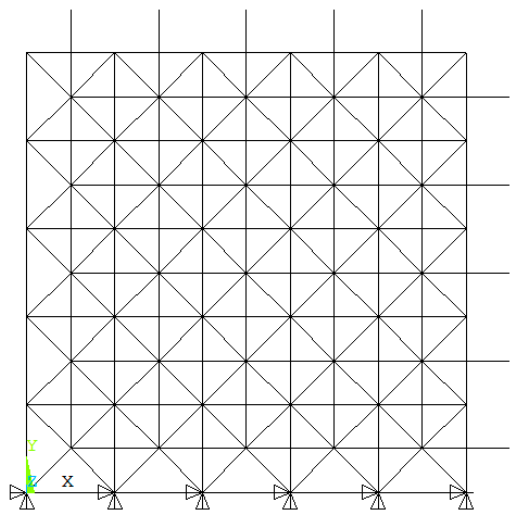

(b)

Figure 6. Square pyramid spatial trusses with opposite boundary fixed supports. (a) The boundary condition; (b) a quarter model.

Table 5. Element importance coefficient under different support conditions.

\begin{tabular}{ccccccccc}
\hline $\begin{array}{c}\text { Element } \\
\text { Number }\end{array}$ & $\begin{array}{c}\text { Two } \\
\text { Edges }\end{array}$ & $\begin{array}{c}\text { Four } \\
\text { Edges }\end{array}$ & $\begin{array}{c}\text { Element } \\
\text { Number }\end{array}$ & $\begin{array}{c}\text { Two } \\
\text { Edges }\end{array}$ & $\begin{array}{c}\text { Four } \\
\text { Edges }\end{array}$ & $\begin{array}{c}\text { Element } \\
\text { Number }\end{array}$ & $\begin{array}{c}\text { Two } \\
\text { Edges }\end{array}$ & $\begin{array}{c}\text { Four } \\
\text { Edges }\end{array}$ \\
\hline 2 & 0.0053 & 0 & 96 & 0.0029 & 0.0300 & 298 & 0.0913 & 0.0004 \\
4 & 0.0087 & 0.0004 & 106 & 0.0068 & 0.0031 & 300 & 0.0548 & 0.0065 \\
6 & 0.0093 & 0.0013 & 241 & 0.0475 & 0.0002 & 302 & 0.0519 & 0.0166 \\
8 & 0.0093 & 0.0022 & 260 & 0.0697 & 0.0003 & 304 & 0.0509 & 0.0265 \\
10 & 0.0093 & 0.0029 & 262 & 0.0402 & 0.0052 & 306 & 0.0506 & 0.0326 \\
12 & 0.0093 & 0.0031 & 279 & 0.0856 & 0.0004 & 402 & 0.0064 & 0 \\
64 & 0.0033 & 0.0022 & 281 & 0.0509 & 0.0061 & 406 & 0.0031 & 0.0003 \\
85 & 0.0058 & 0.0029 & 283 & 0.0481 & 0.0157 & 407 & 0.0030 & 0.0011 \\
92 & 0.0029 & 0.0198 & 285 & 0.0473 & 0.0250 & 441 & 0.0041 & 0.0005 \\
94 & 0.0029 & 0.0272 & 287 & 0.0470 & 0.0307 & 442 & 0.0048 & 0.0004 \\
\hline
\end{tabular}

It can be found that the influence of boundary conditions on the element importance is significant. The element importance coefficient of the grid structure with the opposite two edges fixed is higher than that with the surrounding four edges fixed. Under this opposite two edge fixed, the upper chords 6, 8, 10, 12 have the highest importance coefficient, and the lower chord 298 also has a higher importance coefficient. Among the web members, chord 402 has the highest importance coefficient, and the chords 441 and 442 are relatively higher. The important elements of the upper chords, lower chords and web members are located on the side of the fixed support, on the side of free support and in the corner of the plane, respectively. The change of support conditions reduces the importance of the middle members of the upper and lower chords while increasing the importance of the edge members. The important web members are also concentrated in the peripheral corners of the structure.

\subsection{Influence of the Span}

The influence of the span of the grid on the element importance is presented in this subsection. The size of the basic pyramid unit is $4 \mathrm{~m} \times 4 \mathrm{~m}$. The number of the basic unit is changed to form five different grid structures with the numbers of the basic grid of $8 \times 8,8 \times 10,8 \times 12,10 \times 10$, and $10 \times 12$, respectively. The vertical symmetric load, shown in Figure $4 \mathrm{a}$, is used. A quarter model is chosen similarly, according to the symmetry. The importance coefficients of the most important upper chord, lower chord, and web member are given in Table 6, and the corresponding locations are shown in Figure 7. It can be found that the locations of the element with the highest importance coefficients in different grid structures are not affected by the structural span. If the plane projection of the grid structure is square, the most important chords are at the center, while the most important web members are adjacent to the boundary. If the plane projection of the truss is 
rectangular, the most important chords are parallel to the short span around the center part, while the most important web members are also just beside the boundary of the long span.

Table 6. Importance coefficients of the most important elements under different spans.

\begin{tabular}{cccccc}
\hline Number of Basic Pyramid Grids & $\mathbf{8} \times \mathbf{8}$ & $\mathbf{8} \times \mathbf{1 0}$ & $\mathbf{8} \times \mathbf{1 2}$ & $\mathbf{1 0} \times \mathbf{1 0}$ & $\mathbf{1 0} \times \mathbf{1 2}$ \\
\hline Upper chord & 0.0446 & 0.0520 & 0.0511 & 0.0300 & 0.0346 \\
Lower chord & 0.0472 & 0.0554 & 0.0546 & 0.0326 & 0.0377 \\
Web member & 0.0052 & 0.0050 & 0.0046 & 0.0023 & 0.0023 \\
\hline
\end{tabular}

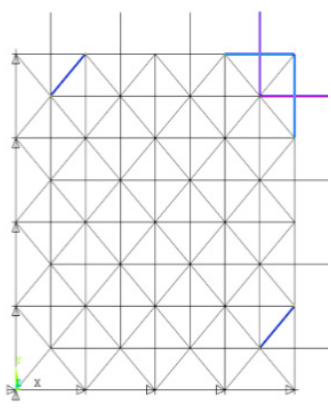

(a)

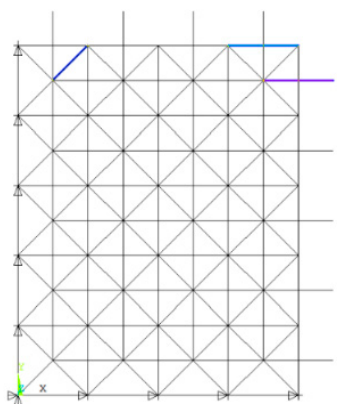

(b)

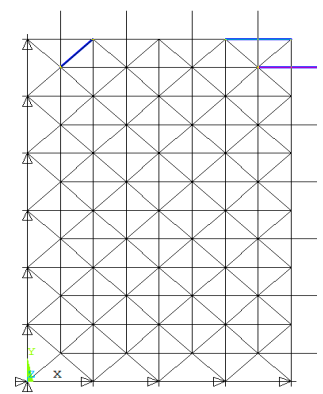

(c)

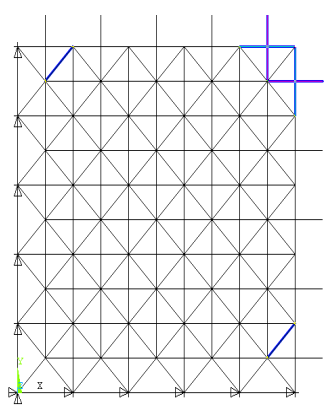

(d)

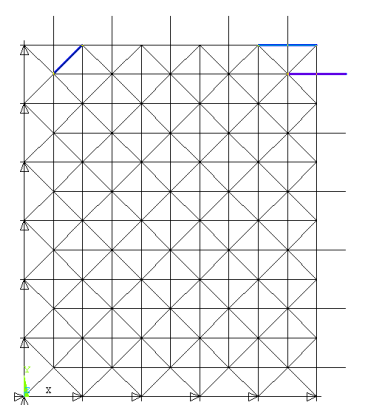

(e)

Figure 7. Locations of the important elements under different truss span. (a) $8 \times 8$; (b) $8 \times 10$; (c) $8 \times 12 ;(\mathbf{d}) 10 \times 10 ;(\mathbf{e}) 10 \times 12$.

\subsection{Influence of Sizes of the Basic Pyramid Grid}

In this subsection, the span of grid structures is kept as $40 \mathrm{~m} \times 40 \mathrm{~m}$. The sizes of the basic pyramid grid are changed with the numbers of the basic unit, which are assumed as $10 \times 16,10 \times 12,10 \times 10$, and $10 \times 8$, respectively. The importance coefficients of the most important elements are given in Table 7 . Similarly, the locations of the important element in different grid structures are not affected by the size of the basic pyramid grid. When the number of basic units increases from $10 \times 8$ to $10 \times 16$, the size of the basic units becomes smaller, which leads to more numbers of elements. The importance coefficient of the most important element is reduced.

Table 7. Importance coefficient of the most important elements under different sizes of basic grids.

\begin{tabular}{ccccc}
\hline Number of Basic Pyramid Grids & $\mathbf{1 0} \times \mathbf{1 6}$ & $\mathbf{1 0} \times \mathbf{1 2}$ & $\mathbf{1 0} \times \mathbf{1 0}$ & $\mathbf{1 0} \times \mathbf{8}$ \\
\hline Upper chord & 0.0228 & 0.0270 & 0.0300 & 0.0361 \\
Lower chord & 0.0234 & 0.0286 & 0.0326 & 0.0394 \\
Web member & 0.0014 & 0.0018 & 0.0023 & 0.0035 \\
\hline
\end{tabular}

For the square pyramid space grid structure, the element importance coefficients of lower chord members are higher than those of upper chord members, and the web members have the lowest importance. Moreover, the important upper and lower chord 
members are located at the center, while the important web members are located near the edge. The distribution will be independent of the geometry, while it will be changed for different load patterns and support conditions.

\section{Effects of the Spatial Grid Topology}

The grid structures with three different topologies are studied in this section, including diagonal square pyramid grids, bi-orthogonal lattice grids, and bi-orthogonal-diagonal lattice grids. The dimension, load level and support conditions are the same as those of square pyramid space grid structures. Similarly, the eighth model is selected to investigate the element importance for these three grid structures.

\subsection{Diagonal Square Pyramid Grids}

A diagonally square pyramid space grid structure, shown in Figure 8, is chosen as a case with cross-section numbers. The details of the cross-section of elements are given in Table 8. The corresponding cross-section are $\Phi 60 \times 4$ (diameter $\times$ thickness), $\Phi 76 \times 4$, $\Phi 89 \times 4, \Phi 114 \times 4, \Phi 140 \times 4, \Phi 159 \times 6$ and $\Phi 159 \times 8$. The eighth model is shown in Figure 9 .

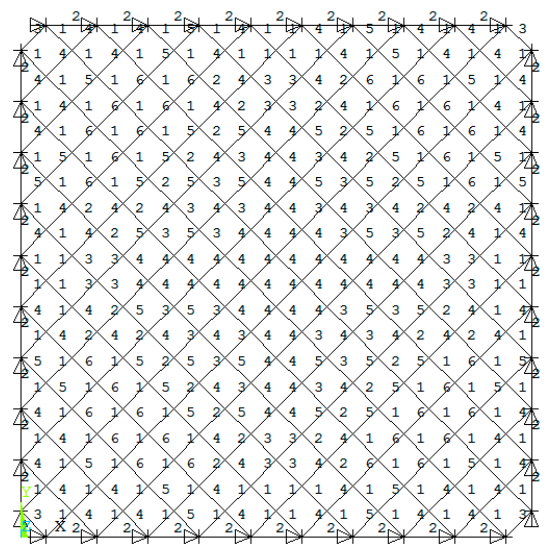

(a)

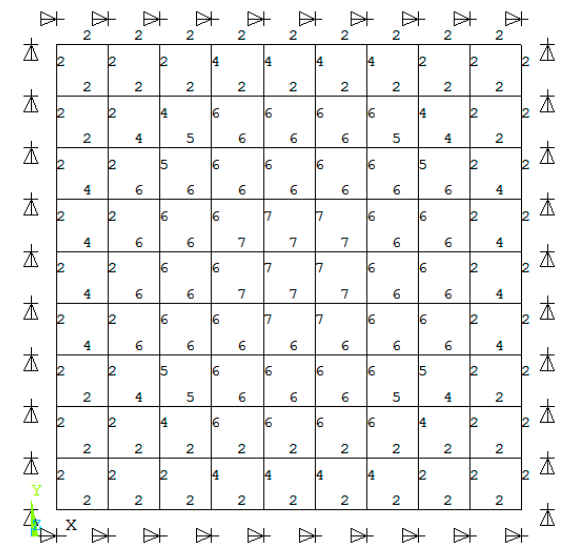

(b)

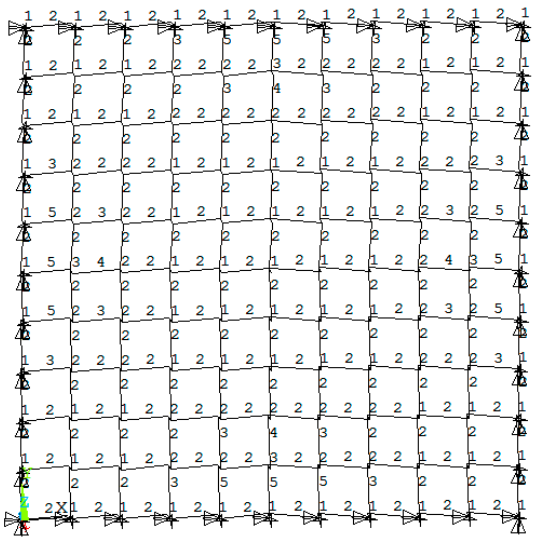

(c)

Figure 8. A diagonally square pyramid space grid structure. (a) Upper chords; (b) lower chords; (c) web members.

Table 8. Details of the cross-section of elements.

\begin{tabular}{cccccccc}
\hline Number & $\mathbf{1}$ & $\mathbf{2}$ & $\mathbf{3}$ & $\mathbf{4}$ & $\mathbf{5}$ & $\mathbf{6}$ & $\mathbf{7}$ \\
\hline Cross-section & $\Phi 60 \times 4$ & $\Phi 76 \times 4$ & $\Phi 89 \times 4$ & $\Phi 114 \times 4$ & $\Phi 140 \times 4$ & $\Phi 159 \times 6$ & $\Phi 159 \times 8$ \\
\hline
\end{tabular}




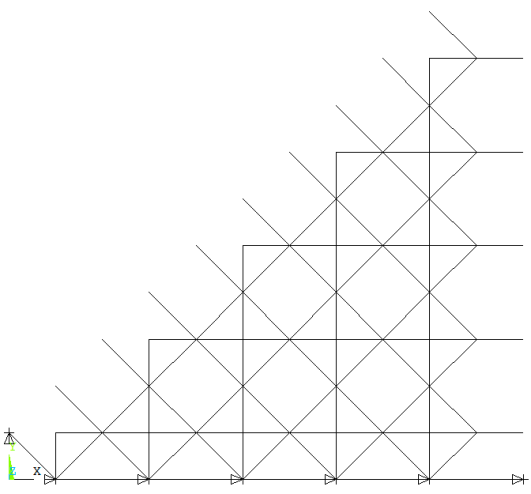

(a)

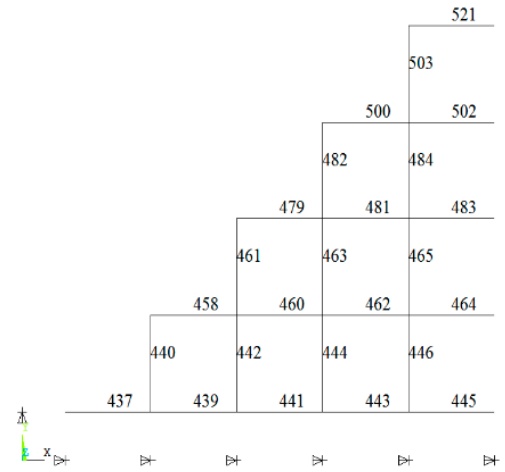

(c)

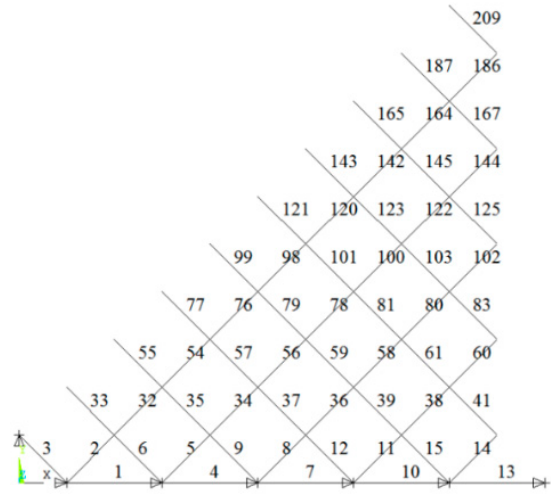

(b)

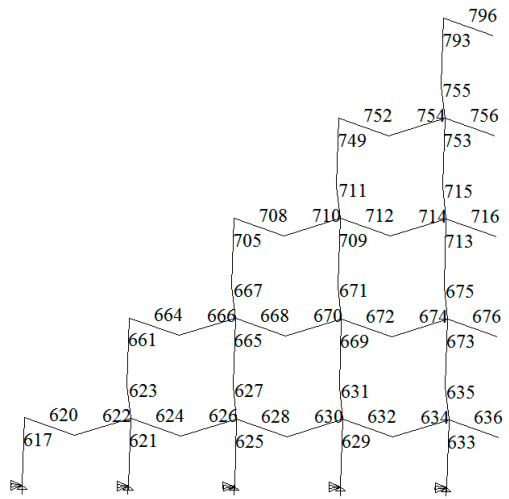

(d)

Figure 9. The eighth model of the diagonal square pyramid grids. (a) Eighth model; (b) number of the top chords; (c) number of the lower chords; (d) number of the diagonal web members.

Element importance coefficients of the diagonal square pyramid grids are given in Table 9. It can be found that the lower chord 521 has the largest element importance coefficient. It is at the center of the grid. The lower chords, 484, 500, 502, 503, which are located at the central part, are also very important. For the upper chord, the importance coefficient of chord 99 is the highest. Chord 635 is the most important element in diagonal web members. The web members, which are parallel to chord 635 , such as chords 627 , $629,631,669,673$, are relatively important. The important web members are close to the boundary.

Table 9. The element importance coefficient $\alpha_{i}$ for the diagonal square pyramid grids.

\begin{tabular}{cccccc}
\hline Element Number & $\boldsymbol{\alpha}_{\boldsymbol{i}}$ & Element Number & $\boldsymbol{\alpha}_{\boldsymbol{i}}$ & Element Number & $\boldsymbol{\alpha}_{\boldsymbol{i}}$ \\
\hline 9 & 0.0106 & 145 & 0.0119 & 502 & 0.0559 \\
12 & 0.0145 & 165 & 0.0105 & 503 & 0.0673 \\
37 & 0.0135 & 442 & 0.0180 & 521 & 0.0686 \\
55 & 0.0126 & 444 & 0.0407 & 627 & 0.0184 \\
57 & 0.0257 & 446 & 0.0414 & 629 & 0.0228 \\
59 & 0.0242 & 461 & 0.0241 & 631 & 0.0363 \\
77 & 0.0244 & 463 & 0.0489 & 633 & 0.0226 \\
79 & 0.0261 & 465 & 0.0527 & 635 & 0.0385 \\
99 & 0.0347 & 479 & 0.0280 & 661 & 0.0010 \\
101 & 0.0192 & 481 & 0.0296 & 669 & 0.0250 \\
103 & 0.0128 & 482 & 0.0542 & 671 & 0.0129 \\
121 & 0.0148 & 483 & 0.0304 & 673 & 0.0275 \\
123 & 0.0102 & 484 & 0.0621 & 675 & 0.0174 \\
143 & 0.0142 & 500 & 0.0558 & 713 & 0.0101 \\
\hline
\end{tabular}




\subsection{Bi-Orthogonal Lattice Grids}

As shown in Figure 10, a bi-orthogonal lattice grid structure is investigated with crosssection numbers. The corresponding cross-section are $\Phi 60 \times 4$ (diameter $\times$ thickness), $\Phi 76 \times 4, \Phi 89 \times 4, \Phi 114 \times 4, \Phi 140 \times 4, \Phi 159 \times 6, \Phi 159 \times 8$, and $\Phi 180 \times 8$, as given in Table 10.

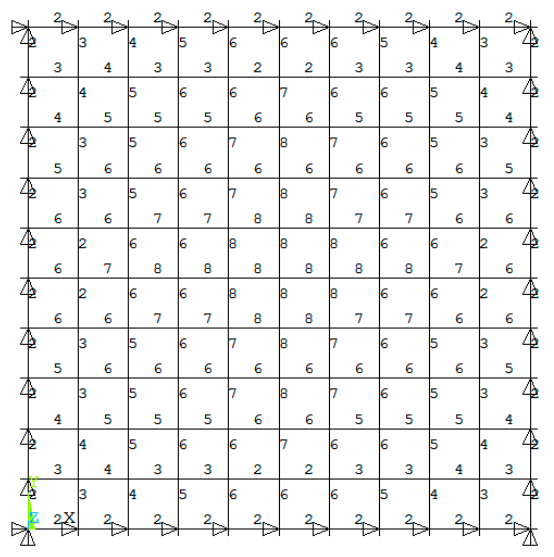

(a)

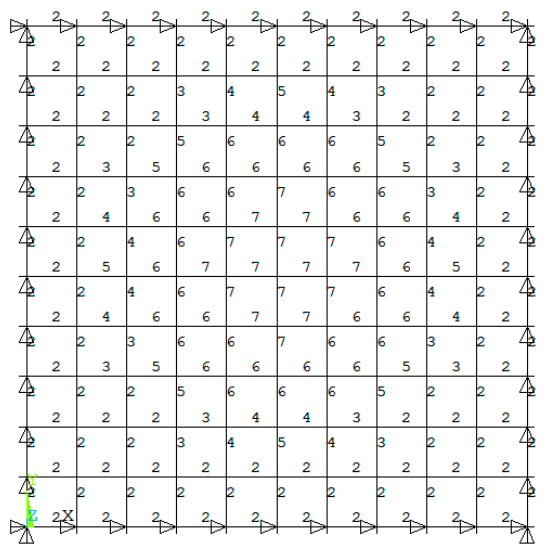

(b)

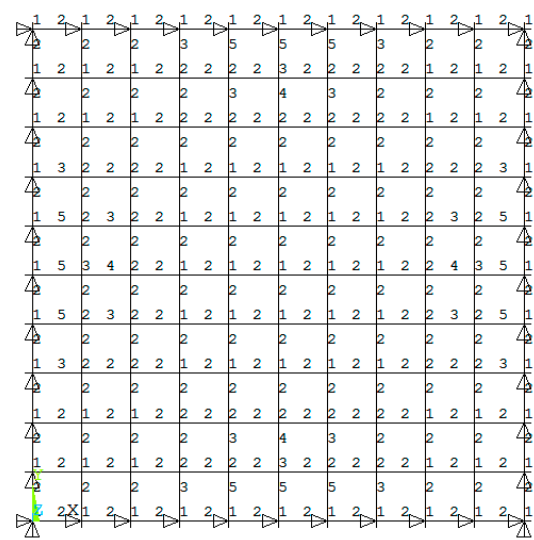

(c)

Figure 10. A bi-orthogonal lattice grid structure. (a) Upper chords; (b) lower chords; (c) web members.

Table 10. Details of the cross-section of elements.

\begin{tabular}{ccccccccc}
\hline Number & $\mathbf{1}$ & $\mathbf{2}$ & $\mathbf{3}$ & $\mathbf{4}$ & $\mathbf{5}$ & $\mathbf{6}$ & $\mathbf{7}$ & $\mathbf{8}$ \\
\hline Cross-section & $\Phi 60 \times 4$ & $\Phi 76 \times 4$ & $\Phi 89 \times 4$ & $\Phi 114 \times 4$ & $\Phi 140 \times 4$ & $\Phi 159 \times 6$ & $\Phi 159 \times 8$ & $\Phi 180 \times 8$ \\
\hline
\end{tabular}

The corresponding eighth model is shown in Figure 11 with element numbers of upper chords, lower chords and web members. Element importance coefficients of the bi-orthogonal lattice grids are given in Table 11. It can be found that the web chord 721 has the largest element importance coefficient. It is at the center of the grid. The important elements of the web members are located in the vicinity of the periphery of the web surface except for the central vertical web member 721 . The important elements of the upper chord are located near the line connecting chord 96 and chord 12 and are distributed in a stripe shape. The important elements of the lower chord are located at the center of the lower chord plane, presenting a blocky distribution. Compared with the diagonal square pyramid, the importance of each part is significantly increased. 


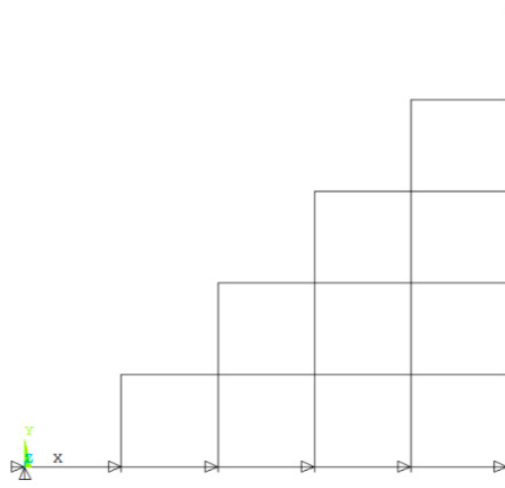

(a)

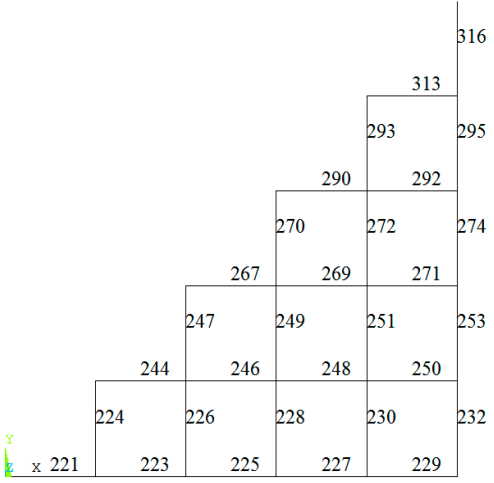

(c)

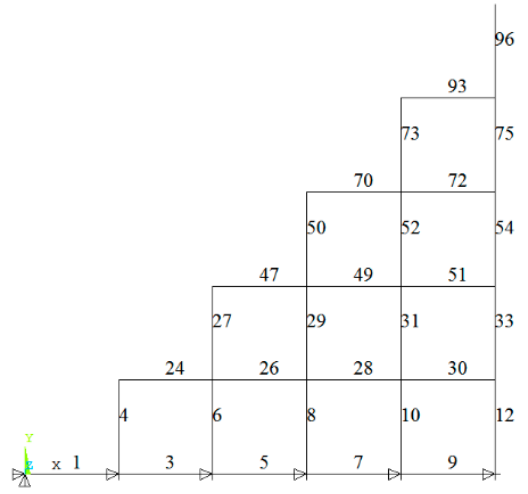

(b)

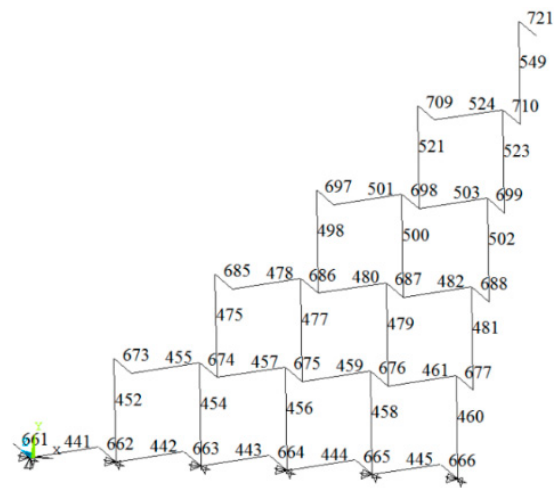

(d)

Figure 11. Bi-orthogonal lattice grid. (a) The eighth of the model; (b) the number of the top chords; (c) the number of the lower chords; (d) the number of the diagonal web members.

Table 11. Importance coefficient $\alpha_{i}$ of bars under vertical uniform load.

\begin{tabular}{cccccc}
\hline Upper Chord Number & $\boldsymbol{\alpha}_{\boldsymbol{i}}$ & Lower Chord Number & $\boldsymbol{\alpha}_{\boldsymbol{i}}$ & Web Member Number & $\boldsymbol{\alpha}_{\boldsymbol{i}}$ \\
\hline 8 & 0.0146 & 73 & 0.0693 & 295 & 0.0667 \\
10 & 0.0259 & 75 & 0.0855 & 313 & 0.0610 \\
12 & 0.0313 & 93 & 0.0703 & 316 & 0.0754 \\
29 & 0.0276 & 96 & 0.0863 & 458 & 0.0257 \\
31 & 0.0464 & 251 & 0.0247 & 460 & 0.0311 \\
33 & 0.0552 & 253 & 0.0298 & 481 & 0.0183 \\
47 & 0.0108 & 270 & 0.0244 & 675 & 0.0174 \\
50 & 0.0347 & 272 & 0.0412 & 677 & 0.0293 \\
52 & 0.0616 & 274 & 0.0493 & 687 & 0.0327 \\
54 & 0.0774 & 290 & 0.0294 & 688 & 0.0199 \\
70 & 0.0379 & 292 & 0.0331 & 0.0528 & 721 \\
72 & 0.0360 & 293 & & & 0.0203 \\
\hline
\end{tabular}

\subsection{Bi-Orthogonal-Diagonal Lattice Grids}

A bi-orthogonal-diagonal lattice grid structure is studied, as shown in Figure 12. The numbers of the cross-section and its details are given in Figure 12 and Table 12, respectively. The corresponding cross-sections are $\Phi 60 \times 4$ (diameter $\times$ thickness), $\Phi 76 \times 4, \Phi 89 \times 4$, $\Phi 114 \times 4, \Phi 140 \times 4$ and $\Phi 159 \times 6$. Its eighth model is chosen to study the element importance, as shown in Figure 13. Element importance coefficients of the bi-orthogonaldiagonal lattice grids are given in Table 13. It can be found that web member 855 has the largest importance coefficient. The vertical chord in the web member is more important. Except for the central vertical web member 855 , the other vertical webs are located near the periphery of the plane. The important member of the upper chord member is located close to the line connecting chord 212 and chord 203, parallel to chord 212, and distributed in a stripe shape. The important elements of the lower chord are located in the central area. The importance of vertical web members cannot be ignored. 


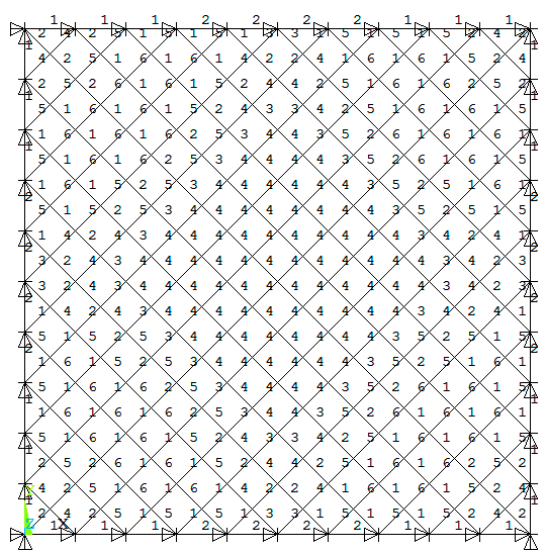

(a)

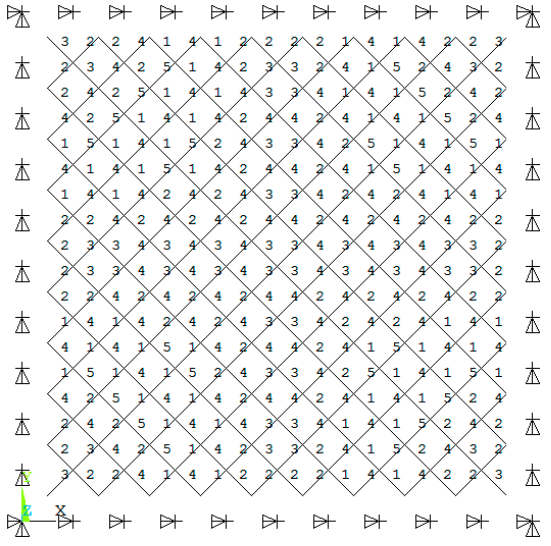

(b)

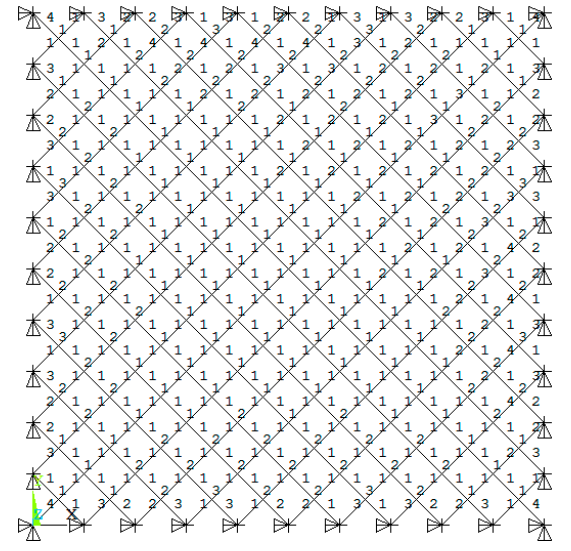

(c)

Figure 12. A bi-orthogonal-diagonal lattice grid structure. (a) Upper chords; (b) lower chords; (c) web members.

Table 12. Details of the cross-section of elements.

\begin{tabular}{ccccccc}
\hline Number & $\mathbf{1}$ & $\mathbf{2}$ & $\mathbf{3}$ & $\mathbf{4}$ & $\mathbf{5}$ & $\mathbf{6}$ \\
\hline Cross-section & $\Phi 60 \times 4$ & $\Phi 76 \times 4$ & $\Phi 89 \times 4$ & $\Phi 114 \times 4$ & $\Phi 140 \times 4$ & $\Phi 159 \times 6$ \\
\hline
\end{tabular}

For the different types of grid structures, there are inconsistent distribution characteristics for the element importance coefficients. The main important lower and upper chord members are concentrated in the center, while the important web members are located near the edge. When the upper chord is arranged in parallel with the support side, the important elements of the upper chords are located in the mid-span and parallel to the support side. When the lower chords are arranged in parallel with the side of the support, the important lower chords are distributed in a block shape in the mid-span. When the upper and lower chords are placed at an angle of $45^{\circ}$ to the side of the support, the important members are close to the supports and parallel to the diagonal of the structure. The different distribution of important members also reveals that the rapid model evaluation on element importances is essential in the conceptual analysis stage, reflecting the influence of geometric topology on the structural safety status. 


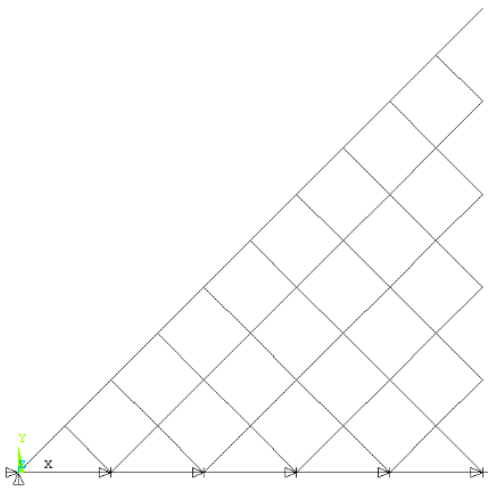

(a)

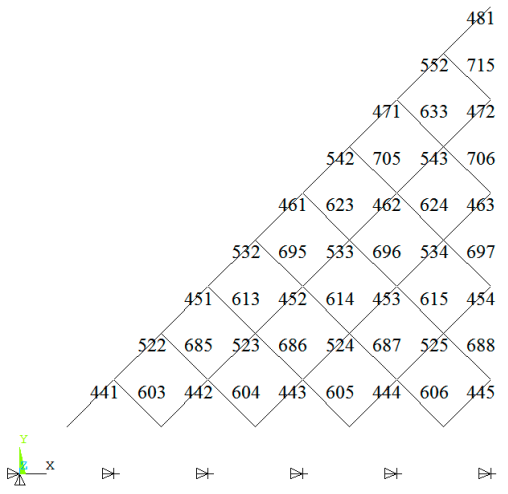

(c)

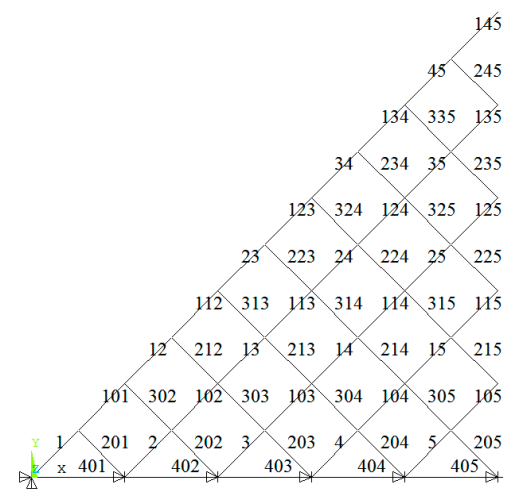

(b)

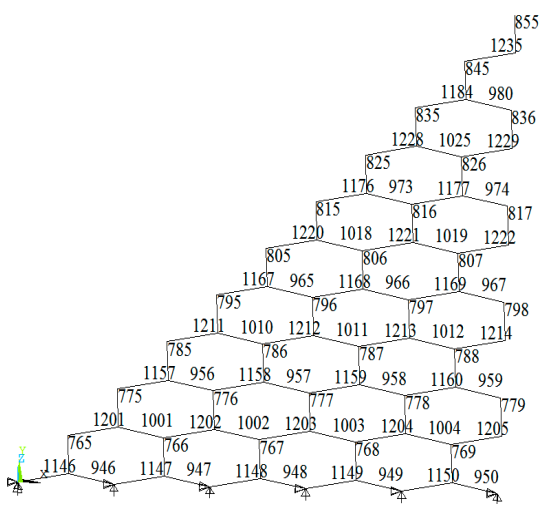

(d)

Figure 13. Bi-orthogonal-diagonal lattice Grid. (a) The eighth model; (b) number of the top chords; (c) number of the lower chords; (d) number of the diagonal web members.

Table 13. Importance coefficient $\alpha_{i}$ of bars under vertical uniform load.

\begin{tabular}{cccccc}
\hline Upper Chord Number & $\alpha_{i}$ & Lower Chord Number & $\boldsymbol{\alpha}_{\boldsymbol{i}}$ & Web Member Number & $\boldsymbol{\alpha}_{\boldsymbol{i}}$ \\
\hline 1 & 0.0109 & 314 & 0.0169 & 685 & 0.0130 \\
201 & 0.0175 & 315 & 0.0103 & 686 & 0.0118 \\
202 & 0.0204 & 324 & 0.0143 & 695 & 0.0165 \\
203 & 0.0152 & 463 & 0.0123 & 696 & 0.0145 \\
212 & 0.0253 & 472 & 0.0165 & 697 & 0.0114 \\
213 & 0.0205 & 481 & 0.0148 & 705 & 0.0176 \\
214 & 0.0134 & 543 & 0.0127 & 706 & 0.0162 \\
223 & 0.0187 & 552 & 0.0131 & 715 & 0.0190 \\
224 & 0.0129 & 613 & 0.0155 & 767 & 0.0149 \\
234 & 0.0104 & 614 & 0.0136 & 768 & 0.0187 \\
302 & 0.0237 & 615 & 0.0105 & 769 & 0.0202 \\
303 & 0.0223 & 623 & 0.0170 & 778 & 0.0101 \\
304 & 0.0155 & 624 & 0.0153 & 0.0186 & 779 \\
313 & 0.0229 & 633 & & 855 & 0.0104 \\
\hline
\end{tabular}

\section{Conclusions}

This paper proposes a rapid model evaluation method on element importances of grid structures based on the element strain energy and element removal technology. The effects of the loading pattern, the boundary condition, and geometric parameters of square pyramid grid structures are investigated. Moreover, three types of spatial grids, diagonal square pyramid grids, bi-orthogonal lattice grids, and bi-orthogonal-diagonal lattice grids, are chosen to examine the influence of the topology on the element importance. The main conclusions are as follows.

(1) For square pyramid grid structures, the results show that the lower and top chords are more important than the diagonal web members. The importance coefficients of 
the elements are different under different load patterns, and the order of importance of the elements is also changed when subjected to horizontal loads.

(2) The change of the support condition reduces the importance of the upper and lower chords in the center area for square pyramid grid structures. The effects of the structural span and the size of the basic pyramid grid can be ignored for the location of the most important members.

(3) There are different distribution characteristics for the element importance coefficients for grid structures with different topologies. The location of important elements for the upper chords, the lower chords and the web members are dependent on the relationship between the arrangement of these members and support sides.

Based on the proposed method in this paper, the rapid model and element evaluation can be performed in the conceptual analysis stage. It is an efficient way for the robustness design after the preliminary design of general grid structures. At last, it is easy to be integrated into the existing platform due to its simplicity and efficiency.

Author Contributions: Conceptualization, J.C. and J.F.; methodology, L.W. and Y.X.; software, Q.Z. and Y.X.; validation, L.W. and L.Z.; formal analysis, Q.Z.; investigation, L.W. and L.Z.; resources, L.W.; data curation, L.W.; writing-original draft preparation, L.W.; writing-review and editing, Q.Z.; visualization, Y.X.; supervision, J.C. and J.F.; project administration, J.C.; funding acquisition, J.C. and J.F. All authors have read and agreed to the published version of the manuscript.

Funding: This research was funded by [National Natural Science Foundation of China] grant number [U1937202 and 51878147].

Institutional Review Board Statement: Not applicable.

Informed Consent Statement: Not applicable.

Data Availability Statement: No new data were created or analyzed in this study. Data sharing is not applicable to this article.

Acknowledgments: Not applicable.

Conflicts of Interest: The authors declare no conflict of interest.

\section{References}

1. Ameri, M.R.; Massumi, A.; Masoomi, H. Effect of structural redundancy on progressive collapse resistance enhancement in RC frame structures. J. Perform. Constr. Facil. 2019, 33, 04018092. [CrossRef]

2. Mucedero, G.; Brunesi, E.; Parisi, F. Progressive collapse resistance of framed buildings with partially encased composite beams. J. Build. Eng. 2021, 38, 102228. [CrossRef]

3. Kang, S.; Tan, K.H. Behaviour of precast concrete beam-column sub-assemblages subject to column removal. Eng. Struct. 2015, 93, 85-96. [CrossRef]

4. $\quad$ Feng, J.; Sun, Y.; Xu, Y.; Wang, F.; Zhang, Q.; Cai, J. Robustness analysis and important element ealuation method of truss structures. Buildings 2021, 11, 436. [CrossRef]

5. Feng, J.; Ren, S.; Zhang, Q.; Xu, Y.; Li, J.; Cai, J. Numerical investigation on the buckling behavior of damaged steel members constrained by outer tubes. Structures 2021, 34, 1068-1079. [CrossRef]

6. Foraboschi, P. Versatility of steel in correcting construction deficiencies and in seismic retrofitting of RC buildings. J. Build. Eng. 2016, 8, 107-122. [CrossRef]

7. Meloni, M.; Cai, J.; Zhang, Q.; Lee, S.-H.D.; Li, M.; Ma, R.; Parashkevov, T.E.; Feng, J. Engineering Origami: A comprehensive review of recent applications, design methods, and tools. Adv. Sci. 2021, 8, 2000636. [CrossRef]

8. Zhang, Q.; Pan, N.; Meloni, M.; Lu, D.; Cai, J.; Feng, J. Reliability analysis of radially retractable roofs with revolute joint clearances. Reliab. Eng. Syst. Saf. 2021, 208, 107401. [CrossRef]

9. Shayanfar, M.A.; Javidan, M.M. Progressive collapse-resisting mechanisms and robustness of RC frame-shear wall structures. J. Perform. Constr. Facil. 2017, 31, 04017045. [CrossRef]

10. Stephen, D.; Lam, D.; Forth, J.; Ye, J.; Tsavdaridis, K.D. An evaluation of modelling approaches and column removal time on progressive collapse of building. J. Constr. Steel Res. 2019, 153, 243-253. [CrossRef]

11. Elsanadedy, H.M. New moment-resisting beam-column joints to increase progressive collapse resistance of precast concrete buildings. J. Build. Eng. 2021, 44, 102884. [CrossRef]

12. Fu, F.; Parke GA, R. Assessment of the progressive collapse resistance of double-layer grid space structures using implicit and explicit methods. Int. J. Steel Struct. 2018, 18, 831-842. [CrossRef] 
13. Tian, L.; Wei, J.; Hao, J. Anti-progressive collapse mechanism of long-span single-layer spatial grid structures. J. Constr. Steel Res. 2018, 144, 270-282. [CrossRef]

14. Wei, J.; Tian, L.; Hao, J. Improving the progressive collapse resistance of long-span single-layer spatial grid structures. Constr. Build. Mater. 2018, 171, 96-108. [CrossRef]

15. Adam, J.M.; Parisi, F.; Sagaseta, J.; Lu, X. Research and practice on progressive collapse and robustness of building structures in the 21st century. Eng. Struct. 2018, 173, 122-149. [CrossRef]

16. Pandey, P.C.; Barai, S.V. Structural sensitivity as a measure of redundancy. J. Struct. Eng. ASCE 1997, 123, 360-364. [CrossRef]

17. Agarwal, J.; Blockley, D.; Woodman, N. Vulnerability of structural systems. Struct. Saf. 2003, 25, 263-286. [CrossRef]

18. Wu, X.; Blockley, D.I.; Woodman, N.J. Vulnerability of structural systems.2. failure scenarios. Civ. Eng. Syst. 1993, 10, 319-333. [CrossRef]

19. Wu, X.; Blockley, D.I.; Woodman, N.J. Vulnerability of structural systems.1. rings and clusters. Civ. Eng. Syst. 1993, 10, 301-317. [CrossRef]

20. Beeby, A.W.; Institution, O.S.E. Safety of structures, and a new approach to robustness. Struct. Eng. 1999, 77, 16-21.

21. Gharaibeh, E.S.; Frangopol, D.M.; Onoufriou, T. Reliability-based importance assessment of structural members with applications to complex structures. Comput. Struct. 2002, 80, 1113-1131. [CrossRef]

22. Izzuddin, B.A.; Vlassis, A.G.; Elghazouli, A.Y.; Nethercot, D.A. Progressive collapse of multi-storey buildings due to sudden column loss-Part I: Simplified assessment framework. Eng. Struct. 2018, 30, 1308-1318. [CrossRef]

23. Nafday, A.M. System safety performance metrics for skeletal structures. J. Struct. Eng. -ASCE 2008, 134, 499-504. [CrossRef]

24. Gao, Y.; Liu, X. Importance coefficients of components in evaluation of structure robustness. Chin. J. Rock Mech. Eng. 2008, 27, 575-2584. (In Chinese)

25. Khandelwal, K.; El-Tawil, S. Pushdown resistance as a measure of robustness in progressive collapse analysis. Eng. Struct. 2011, 33, 2653-2661. [CrossRef]

26. Brunesi, E.; Nascimbene, R.; Parisi, F.; Augenti, N. Progressive collapse fragility of reinforced concrete framed structures through incremental dynamic analysis. Eng. Struct. 2015, 104, 65-79. [CrossRef]

27. Li, Y.; Lu, X.; Guan, H.; Ren, P.; Qian, L. Probability-based progressive collapse-resistant assessment for reinforced concrete frame structures. Adv. Struct. Eng. 2016, 19, 1723-1735. [CrossRef]

28. Gordini, M.; Habibi, M.R.; Sheidaii, M.R.; Tahamouliroudsari, M. Reliability analysis of double-layer domes with stochastic geometric imperfections. Adv. Comput. Des. 2017, 2, 133-146. [CrossRef]

29. Cai, J.; Jia, W.; Feng, J.; Wang, F.; Xu, Y. Applications of stiffness-based evaluation method to element importance of truss systems. J. Civ. Eng. Manag. 2017, 23, 562-572. [CrossRef] 